\title{
The British Geriatrics Society
}

At a general meeting of the Medical Society for the Care of the Elderly, held in Belfast on September 24, the title of the Society was changed to "The British Geriatrics Society". It was also agreed to retain the former name as a subtitle.

At the same meeting Lord Amulree was re-elected President of the Society. Dr. A. N. ExtonSmith (Hon. Secretary), Dr. P. Arnold (Hon. Deputy Secretary) and Dr. J. JV. Agate (Hon. Treasurer) were also re-elected. Dr. T.N. Rudd was elected to the new office of Honorary Editorial Secretary.

The next general meeting of the Society is to be held in Bristol on April 1st and 2nd, 1960. Further information may be obtained from Dr. A. TV. Exton-Smith, Whittington Hospital (Highgate Wing), Dartmouth Park Hill, London N. 19.

Medical Society for the Care of the Elderly The Medical Society for the Care of the Elderly, at its Annual Meeting in Belfast on September 24, 1959, unanimously decided to change its title to "The British Geriatrics Society", the original name being retained as a subtitle. When the Society was originally named, the word "geriatrics" was little understood and sometimes unacceptable in Great Britain. In order to clarify the nature of the Society and to bring its title into line with similar societies in other countries, the present change has been decided upon. The objects and constitution of the Society remain unaltered. Honour to Dr. Marjory Warren

At the Belfast Meeting of the British Geriatrics Society (Medical Society for the Care of the Elderly) on September 24, 1959, members were shown over Wakehurst House, the new Geriatric Department of the Belfast City Hospital. This occasion was taken to unveil, in the presence of Dr. Marjory Warren, of Isleworth, Middlesex, a plaque over the entrance to a ward, the reading being as follows:

"The Marjory Warren Ward. Her pioneer medical work for old people in these islands inspired the reforms which began in this ward in June 1948."

Dr. Warren's many friends will be delighted at this recognition of her outstanding contribution to medicine. The new department is under the direction of Dr. G.F. Adams, Consultant Physician to the Geriatric Unit.

The autumn meeting of the British Geriatrics Society (Medical Society for the Care of the Elderly) was held in Belfast, September 24-26, 1959, and was addressed by members of the Medical Staff of the Belfast Hospitals and officials of the Ulster Ministry of Health and Local Government. Of particular interest to geriatric workers, a paper by Mr. S.A. Vincent, F.R.C.S., Surgeon, Belfast City Hospital, described experiments with the post-mortem urinary bladder, which showed that upward displacement of the base closes the bladder outlet, thus inhibiting micturition. That a similar mechanism is effective during life is indicated by the finding that a special belt, fitted with an inflatable perineal pad, exerting pressure in the anal region, has been found effective in preventing nocturnal enuresis in adolescents. The methods have been found difficult to apply to geriatric patients, but encouraging results are being obtained by inducing patients to sit on anal pads. This research is proceeding, and a full report will be published in the 
urological press early next year. Meanwhile, it is hoped that a brief interim account of Mr. Vincent's work will appear in the next issue of this journal.

A valuable symposium on "Hospital Responsibility for Geriatric Services" was contributed by Dr. C. T. Andrews and Dr. T.S. Wilson (Truro), Dr. H. Droller (Leeds) and Dr. J. McLeod (Belfast). Dr. Andrews' paper, which was of outstanding interest, will, we hope, be printed in an early issue of Gerontologia Clinica. Among other important

Congresses - Kongresse - Congrès

323

points he made an appeal for adequate staffing of geriatric services, so that time should be available to make possible the growth of that body of knowledge about health and disease in old age which is the basis of sound method. He also emphasized the need for co-operation of psychiatrists and geriatrists in the care of the aged psychiatric sick and the establishment of departments where the two specialities would work closely together.

Dr. Wilson discussed long-term care of the older patient and spoke in favour of small "long-term annexes", taking 30-40 patients, numerous hospitals of this nature being dispersed within the area being served. In these, emphasis should be placed on the social needs of the patient, the convenience of patients' visitors being important. It is important, too, to avoid an atmosphere of "institutionalization". To secure the best results, patients should in the first instance be visited in their homes by the geriatric physician and social worker, and be admitted to the active-treatment ward, where careful assessment would take place, before their being transferred to the Long-stay Annex.

Dr. Droller discussed the role of the Geriatric Out-patient Department and the places of such therapeutic aids, as Home Physiotherapy. In this matter, ignorance of the economic factors involved is holding up future planning, and a new enquiry is needed into the comparative costs of Out-patient and Domiciliary Physiotherapy. Dr. McLeod discussed patients' fears of hospital, and the need for developing the attitude that admission to hospital was evidence of administrative failure to supply adequate home care. He felt that "education" of the medical and allied professions in the care of the aged was an important function of a geriatric unit.

As sound administrative principles are the basis of successful geriatrics, it was felt that these papers made an outstanding contribution to the highly successful meeting.

Fifth International Congress of Gerontology

The International Association of Gerontology has selected San Francisco, California, as the site for its Fifth International Congress of Gerontology. The dates will be August 7 to 12, 1960. On the basis of the interest already shown in the Congress it is expected that between 1500 and 2000 persons, from every continent, will participate in the Congress.

The Program - The program of the Congress will be planned in four sections: The Biological Sciences; Clinical Medicine; Psychology and the Social Sciences, and Social Welfare. Each section will hold six scientific sessions for the presentation of papers. These four scientific sessions will meet simultaneously. Each section's program committee will be responsible for planning a general symposium to be attended by all Congress participants. In addition there will be two plenary sessions and at least one open public meeting. In order to allow the widest possible latitude for the scientific papers, there will be no over-all Congress theme. English will be the official language for the Congress.

Information on the selection of papers is set forth in the attached notice. Its instructions should then be followed closely. 
The Congress has been granted funds which will make it possible to offer some financial assistance to those whose papers will be accepted for presentation and who will require such assistance.

Registration - It is highly desirable that as many as possible register for the Congress well in advance of the opening date. The registration fee will be $\$ 25.00$ for all who register before May 31,1960 . Thereafter the registration fee will be $\$ 30.00$. Those desiring to register in advance should so inform the President of the Congress. They will be sent the necessary forms.

Exhibits - There will be ample space immediately adjacent to the meeting rooms for exhibits. All enquiries relative to commercial or scientific exhibits should be addressed to: 